\section{Sacrificio, pureza y traición en el Movimiento de Izquierda Revolucionaria*}

Sacrifice, purity and betrayal in the Revolutionary Left Movement

\author{
TAMARA VidAURRÁZAGA ** \\ Maria Olga RuIz ${ }^{* * *}$
}

\section{Resumen}

El artículo analiza la moral militante del Movimiento de Izquierda Revolucionaria de Chile, organización política que adoptó la lucha armada como principal estrategia política en el período 1965-1986. Quienes militaron en la organización debieron acatar diversas

Artículo asociado al Proyecto DI-UFRO No 0049 IR: Olga Ruiz $y$ al Proyecto CONICYT-FONDECYT No 11170200 IR: Tamara Vidaurrazaga.

** Instituto de la Mujer, Compañía 1068, oficina 506, tvidaurrazaga@ insmujer.cl

*** Universidad de La Frontera, Francisco Salazar 01145, olga.ruiz@ ufrontera.cl normas de comportamiento y un universo valórico cuyo eje central descansaba en el mandato de sacrificio y entrega total a la causa revolucionaria, supeditando la vida privada e íntima a las urgencias políticas establecidas por la organización. Ello provocó diversas tensiones y conflictos entre la vida pública-militante y la vida privada- familiar de sus integrantes.

Palabras clave: sacrificio, pureza, traición, revolución, política.

\section{Abstract}

The article analyzes the militant moral of Chile's Revolutionary Left Movement, a political organization that adopted the armed struggle as main political strategy in the period 1965-1986. Those who were members of the organization had to follow various norms of behavior and a universe of values whose central axis was based on the mandate of sacrifice and total surrender to the revolutionary cause, subordinating private and intimate life to political urgencies established by the organization. This caused diverse tensions and conflicts between the public-militant and the private-affective and familiar life of its members.

Key words: Sacrifice, purity, betrayal, revolution, politics 


\section{Introducción}

El presente artículo analiza la experiencia militante de hombres y mujeres que integraron el Movimiento de Izquierda Revolucionario chileno (en adelante, MIR), organización política de izquierda que, a diferencia de los partidos de la llamada izquierda tradicional o gradualista de la época (específicamente, el comunista y socialista), adoptó la lucha armada como principal estrategia para alcanzar el socialismo en el Chile de los años sesenta. El trabajo se aproxima a la moral revolucionaria de la organización y pone el foco en los mandatos y reglas de comportamiento y en las tensiones y conflictos derivados de su aplicación en la vida cotidiana de sus integrantes, quienes al mismo tiempo definieron libremente sus participaciones militantes y se enorgullecían de estas, y a la vez -una vez dentro- debieron asumir exigencias que muchas veces excedieron sus capacidades y deseos. En términos temporales definimos un periodo que va desde la fundación de la organización en 1965 hasta 1986, momento de su división orgánica definitiva.

Esperamos identificar y analizar los rasgos centrales de la cultura política de la organización, poniendo especial atención a los modelos y pautas de conductas que debían guiar la vida de sus militantes. Desde nuestra perspectiva, la moral guevarista adoptada tempranamente por el MIR estableció la centralidad de la revolución, no solo en el plano de la estrategia política, sino también como núcleo de la identidad y de la experiencia militante. Ello supuso que los integrantes del MIR debían subordinar su vida privada y personal a las urgencias y demandas del proyecto revolucionario, cuestión que derivó en una escisión conflictiva entre las dimensiones privada y pública de la vida de la militancia.
Esta aproximación la realizamos desde un análisis de la dimensión cultural de la política desplegada por estos grupos, considerando "los sentidos, sentimientos, lo sagrado, ideas acerca de la moralidad, lo no racional -todos ingredientes de la 'legitimidad' o del 'régimen de consolidación'” (Verdery 1999) y aquello que Norbert Lechner (1986, 1988) entiende como los estilos y modos de hacer y concebir la política, es decir las subjetividades, los marcos valóricos, emocionales y simbólicos -mitos y ritos- que sostienen la acción política.

Con ese propósito aplicamos una metodología cualitativa, interpretativa y de carácter interdisciplinario que puso en diálogo los aportes de distintas disciplinas y enfoques, a saber: historia, antropología, estudios culturales y teoría de género. Respecto a esta última perspectiva analítica, nos hemos centrado en el análisis que algunas autoras realizan de las tensiones público/privada en el marco de proyectos emancipadores y revolucionarios.

Con el objeto de alcanzar estos propósitos analizamos la bibliografía que existe sobre la organización y definimos y examinamos un corpus documental heterogéneo en términos de contenido y temporalidad, como documentos partidarios y personales de la militancia (que incluyó material producido por las propias organizaciones como folletines, prensa periódica, boletines y documentos internos y personales).

Aestecorpus sumamos el análisis de testimonios obtenidos en entrevistas personales realizadas en el marco de investigaciones de postgrado ${ }^{1}$,

Ruiz, M. O. 2014. Historias y memorias de traición. Subjetividad revolucionaria, mandatos militantes y traición en el Partido Revolucionario de los Trabajadores-Ejército Revolucionario del 
así como de un proyecto de investigación intrauniversitario ${ }^{2}$, sumándole testimonios biográficos publicados por militantes ${ }^{3}$. En todos los casos los testimonios refieren a militantes de tiempo completo o profesionales del partido (hombres y mujeres, dirigentes y militantes de base de distintas regiones del país), quienes integraron el MIR desde el periodo previo al Golpe de Estado -en 1973y hasta la desarticulación definitiva de esta orgánica -en 1986-. No incluímos dentro del análisis la experiencia de militantes periféricos o de aquellos que militaron en los frentes intermedios de la organización, justamente porque esa experiencia no exigía la renuncia o supeditación total de la vida privada a la militancia.

La amplitud temporal considerada para este análisis permite revisar diferentes periodos de la organización en los que, con distintos grados de intensidad, se manifiestaron los rasgos principales de una cultura política particular que distinguió al MIR de otras organizaciones de izquierda de la época. Hay que señalar que al hablar de cultura política

Pueblo (PRT-ERP), Montoneros y el Movimiento de Izquierda Revolucionaria (MIR) en las décadas del sesenta y setenta. Tesis para optar al grado de Doctora en Estudios Latinoamericanos, Universidad de Chile, Santiago, y de Vidaurrázaga T. 2006. Mujeres en rojo y negro. Reconstrucción de memoria de tres mujeres miristas (1971-1990). Centro de estudios de género en América Latina, Universidad de Chile. Tesis para optar al grado de magíster y, Vidaurrázaga T. 2016. Las combatientes. Militancias femeninas en la nueva izquierda revolucionaria latinoamericana: miristas chilenas y tupamaras uruguayas. Centro de Estudios Latinoamericanos, Universidad de Chile. Tesis para optar al grado de doctora en Estudios Latinoamericanos.

2 Proyecto Di UFRO La historia de la izquierda revolucionaria conosureña de los sesenta y setenta desde una perspectiva cultural. 2018

3 Los testimonios son referidos con nombre y apellido real o seudónimo dependiendo del tipo de autorización expresamente obtenida en el caso de las entrevistas personales. no la estamos entendiendo como una suerte de entidad reificada y externa a los individuos y a los contextos en que ellos actuaron. Por el contrario, existió una relación dinámica de mutua interacción entre esas representaciones y símbolos y los procesos históricos en que se desenvolvían los sujetos. Por ejemplo, la voluntad de renuncia y la ética sacrificial se manifestaron de modo diferente dependiendo de si la posibilidad de muerte era inminente (como en el escenario postgolpe) o en el primer año del gobierno de la Unidad Popular. La experiencia viva de esos marcos valóricos y el peso que adquirían en la vida cotidiana de los militantes dependía, evidentemente, del escenario concreto en que ellos se situaban.

Todos los testimonios analizados, fueron realizados en el periodo post-dictatorial y -por tanto- de manera retrospectiva a la experiencia de la militancia, y en el marco de una organización que fue derrotada y no tuvo continuidad orgánica. Por ello, es central comprender el testimonio como un ejercicio a posteriori en el que se reelabora la propia historia desde la actualidad, y por tanto se busca coherencia con el presente. Tal como señala la socióloga argentina Alejandra Oberti (2014), a través del testimonio podemos acceder a todo un universo de significaciones que permite comprender mejor las dimensiones subjetivas de esa militancia, que en sus relatos intenta volver comprensible experiencias que a la luz de las derrotas y reconfiguraciones políticas y culturales posteriores pueden volverse inaprehensibles. Estos relatos permiten también, y de un modo privilegiado, asomarse a la dimensión cotidiana de la política, a los modos en que esos idearios se expresaban y desplegaban en el día a día de los sujetos. 


\section{Dentro de la revolución, todo. Fuera de la revolución, nada.}

El historiador chileno Igor Goicovic señala que "no existió un MIR a través de la historia de esta organización, sino que al menos tres". (Goicovic 2016: 14). Esta afirmación evidencia que hubo distintos momentos de la organización, cada uno de ellos claramente diferenciados. El primer MIR sería el que existió entre 1965 (año de su fundación) y 1967, etapa fundacional en la que convergieron diversas tendencias revolucionarias con escasa capacidad de incidir en la realidad política nacional (Palieraki 2014; Salinas 2013; Sandoval 2014; Vitale 1999). A este momento lo sucedió un MIR marcado por el pensamiento castro-guevarista entre los años 1967 y 1975, período en que la organización creció en forma significativa y logró una importante incidencia en el escenario político, en especial en el período del gobierno de la Unidad Popular (Leiva 2010; Pinto 2006; Gaudichaud 2004; Naranjo, Ahumada, Garcés y Pinto 2004; Pérez 2003; Ortega y Radrigán 1998). Luego de la primera gran derrota ocurrida a fines de 1975, el MIR se reestructuró en el marco de la llamada "Operación Retorno", plan que consideró el ingreso clandestino a Chile de militantes que se encontraban en el exterior para luchar en contra de la dictadura encabezada por Augusto Pinochet. De modo que entre 1978 y 1986 la organización participó activamente de la resistencia popular antidictatorial con militantes que ingresaron clandestinamente a Chile desde el exilio y jóvenes que estando en el país se sumaron a sus filas (Palma 2012; Silva 2011; Vera 2011; Leiva 2010; Pinto 2006; Pérez 2003). Ahora bien, más allá de la identificación de etapas en la historia del MIR, creemos que es posible establecer continuidades en el plano moral y cultural de esta organización. Puesto que, si bien existen contextos específicos en los que el MIR definió estrategias y adoptó tácticas diferentes, es posible hablar de un ethos mirista (Ortiz 2013; Ruiz 2018) que se manifestó a lo largo de toda su trayectoria organizativa y que más aún, operó como núcleo articulador de la identidad militante en los distintos períodos, cuestión que el propio Goicovic reconoce.

Justamente, ese núcleo cultural es lo que hace posible reconocer la existencia de una organización cuya historia descansa no sólo en estrategias políticas y principios ideológicos, sino también en una identidad colectiva que ha sobrevivido incluso a las estructuras formales de la organización (Subercaseaux 2004).

En relación a esta dimensión de la experiencia militante, es posible señalar que un rasgo compartido por quienes militaron en el MIR fue que organizaron sus vidas sobre el eje de la revolución. Parafraseando al propio Guevara, no había vida fuera de ella, precepto que fue ampliamente cumplido, integrado y demandado por esta comunidad política. La comprensión de la revolución como totalidad (Carnovale 2011) supuso postergar todo aquello que estuviese fuera de sus contornos. Así, quienes se jactaban de tener una militancia ejemplar relegaron a un plano periférico la dimensión íntima y privada de sus vidas en pos del proyecto colectivo y público de la revolución. Ello incluía a sus familias, parejas, hijos e hijas, los desarrollos intelectuales, los placeres privados, es decir, todo aquello que el filósofo argentino Nicolás Casullo (2007) ha llamado -con ironía- cuestiones sin importancia. Aquello que no cabía dentro del proyecto quedaba fuera de las prioridades y posibilidades, y cualquier cuestionamiento a ese ordenamiento jerárquico del mundo, que asignaba el primerísimo lugar 
a la causa revolucionaria podía ser catalogado como desviación burguesa 0 , incluso, de traición.

Los testimonios de quienes militaron en esta orgánica expresan cómo las vocaciones personales y estudios, podían continuarse cuando eran útiles para la lucha, o suspenderse cuando esas energías se requerían en otra parte o misión. El mismo Guevara, paradigma del buen revolucionario, dejó a su familia de origen y su país natal, renunció a los privilegios de su clase y al desarrollo de su vocación por la medicina, abandonó a su esposa, a sus hijos e hijas y los cargos que tuvo en el gobierno cubano. Una y otra vez demostró con su vida -y con su muerte- que nada podía anteponerse a la vida revolucionaria, y su ejemplo quiso ser emulado por toda una generación de jóvenes militantes.

En relación al sacrificio de lo personal, el intelectual argentino Horacio Tarcus, realiza un interesante análisis en el que identifica elementos religiosos en las que él denomina "sectas políticas", organizaciones en que se promueve el abandono de lo privado en favor de la hermandad de la secta. Para el autor:

\footnotetext{
...Se sacrifica la vida privada pero para vivir intensamente esta hermandad absoluta, que además se ramifica por el mundo. La imagen de otros miembros, remotos, desconocidos, en distintas latitudes, comprometidos en el mismo ideal, se torna excelsa y reafirma la propia fe. La secta no atrae gente sumisa: al contrario, seduce (...) a los corazones exigentes y ambiciosos (Tarcus 1998:54)
}

El abandono, la renuncia y el sacrificio tenían una recompensa inmediata: la hermandad absoluta que además traspasaba las fronteras nacionales y se expandía por el mundo. Las redes del ideal común eran extensas: la hermandad de revolucionarios y revolucionarias se transformaba en la familia que reemplazaba y superaba a la familia sanguínea. Así, los abandonos y postergaciones tenían una razón de ser superior a cualquier necesidad privadaindividual: una transformación radical que mejoraría la vida de las grandes mayorías. En tanto, las minorías cercanas: hijos, hijas, madres, padres, parejas, eran parte de esas cuestiones sin importancia que podían esperar. En ocasiones, la espera significaba unos meses o años. Otras, una década entera. En el caso de quienes morían en la lucha, ese momento posterior nunca llegó. Para aquellos que sobrevivieron fue más difícil aún: el tiempo ausente no se recompuso y las trizas en los vínculos con esas minorías cercanas quedaron como huella imperecedera de la opción tomada en la época de la revolución.

La dedicación exclusiva y plena a la militancia aparece como un tema recurrente en los testimonios de quienes integraron el MIR. Si bien otras organizaciones chilenas de la época también demandaron una entrega similar a sus integrantes, esta exigencia es recordada por los ex miristas como un elemento diferenciador y distintivo. La relevancia asignada a esta dimensión de la experiencia militante puede dimensionarse en la medida que, para muchos de ellos, el ingreso a la organización significó un quiebre radical en términos biográficos, que marcó un antes y un después en sus historias de vida, justamente porque supuso una reestructuración vital, reordenamiento que implicó renuncias, abandonos, así como el ingreso a un mundo político, social y afectivo nuevo y prometedor.

Lucía Sepúlveda, ex militante, señala que era preciso "dedicar prácticamente el noventa y nueve por ciento de tu tiempo a las tareas 
revolucionarias, entonces prácticamente tu vida se convertía en la vida del partido" (Entrevista 2014). De este modo, el ingreso a la organización supuso asumir un compromiso vital que demandó relegar todo aquello que distrajera, obstaculizara o frenara lo considerado verdaderamente importante. Desde esta perspectiva, la vida debía ser por y para el partido. Tal como recuerda Patricia Zalaquett respecto a ese período:

\footnotetext{
la militancia era (...) un compromiso y una decisión de vida y uno tenía que postergar todo lo demás, llamemos profesión, familia, tiempo... o, entretenciones. (...) Yo era puro partido no más, esa era mi militancia todas las horas y los días... (Entrevista 2013)
}

Reclamar tiempo y/o espacio para asuntos personales, para el descanso o la diversión, era observado como una superficialidad o desviación que expresaba una falta de compromiso con el proyecto.

La idea de pureza está asociada al altruismo de la lucha, a una suerte de ascetismo revolucionario que encontraba sentido en la promesa emancipadora de la revolución. Entregar la vida para conquistar el bienestar de todos los oprimidos fue la expresión máxima de la pureza, en oposición a la contaminación de los placeres burgueses que ofrecía el capitalismo.

Este pensamiento dicotómico basado en oposiciones binarias individuo/colectivo, pureza/contaminación, lealtad/traición, no ofrecía solución de continuidad a los hombres y mujeres que se sumaron a estas organizaciones y que debieron, forzosamente, elegir entre una y otra posibilidad, sin opción para la gama de grisáceos posibles en toda experiencia humana.

Sin tiempo ni lugar para todo aquello que quedaba afuera de la revolución, los espacios y los ritmos de la vida militante se estrecharon y aceleraron entorno a un mismo eje: el partido. Esta dinámica, se agudizó en períodos de clandestinidad, aunque no estuvo ausente durante los tres años del gobierno de la Unidad Popular. Arinda Ojeda, militante, que durante ese período democrático estaba emparejada y tenía un hijo pequeño lo recuerda así:

\begin{abstract}
...eran esos años caóticos donde yo no dormía prácticamente. Si lo resistía es porque tenía esa edad, porque trabajaba, después me iba a la Universidad, después a veces había reuniones que me iban a buscar a la Universidad a las doce de la noche. La reunión era de doce a seis de la mañana, llegaba a mi casa, me duchaba, me cambiaba de ropa y partía a trabajar a la fábrica como que nada, porque además como no era público tú no podías decir es que estuve en una reunión (Vidaurrázaga 2006:69).
\end{abstract}

Por su parte, Soledad recuerda que el Golpe de Estado del 11 de septiembre de 1973 no solo significó en su vida temor, fractura y sensación de derrota, sino también una suerte de "normalización" de su vida cotidiana. Forzada a suspender sus actividades militantes, comenzó a conocer la normalidad que vivía el resto de la juventud y que ella se había negado por la dedicación total al partido. Obligada a ingresar a un nuevo centro educacional (al ser expulsada del anterior por razones políticas):

\footnotetext{
Empecé a hacer una vida que ni siquiera conocía antes con mis 16 años, como ver tele, ahí recién empecé a ver Música Libre, los programas de la tele, antes yo no veía tele, no salía a fiestas, nunca tuve nada de joven común y corriente (Vidaurrázaga 2006: 142. El subrayado es nuestro).
}

La vida de joven común y corriente, expresa justamente lo que no era la militancia, pues ser mirista era abandonar el mundo de los corrientes para formar parte de un grupo selecto, integrado por "los mejores hijos del pueblo", puros y excepcionales, con una capacidad de entrega ilimitada y a toda prueba. 
Un hito fundamental en la configuración de ese ethos ocurrió en el año 1967, momento en que bajo la conducción de Miguel Enríquez se puso en marcha un proceso de reorganización partidaria en que se resolvió profesionalizar la militancia.

Así, en el documento Sin lastre avanzaremos más rápido, se señaló: "La entrega de sí mismo deberá ser total. La organización decidirá si un militante debe o no trabajar o estudiar, o dónde habitar" (MIR 1969. En: Naranjo, Ahumada, Garcés y Pinto 2004:62). Para cumplir con este nivel de exigencia, el reclutamiento se hizo más riguroso, aplicándose criterios de selectividad con el objetivo de construir un partido de cuadros.

Los cambios y transformaciones implementados por la nueva Dirección reforzaron el mandato guevarista respecto a la entrega total que exigía la lucha revolucionaria. A la noción leninista del partido de cuadros, de acuerdo a la cual el partido debía actuar como una vanguardia formada por "los mejores hijos del pueblo" cuya misión era conducir las masas al socialismo, se sumó el pensamiento guevarista y sus conceptualizaciones acerca de la moral revolucionaria. En esto, la influencia de Guevara fue decisiva, más allá de las críticas que formuló el MIR a la teoría del foco guerrillero, la dimensión moral de la militancia mirista tuvo como núcleo articulador los planteamientos expuestos en El socialismo y el hombre en Cuba y en el Mensaje a la Tricontinental, en particular la noción de "Hombre Nuevo" y la ética sacrificial de la militancia revolucionaria (Fernández 1999).

Otro documento clave para aproximarse a la cultura política mirista y a los modelos, conductas y valores que la organización promovió en sus militantes es Notas para la formación de cuadros (MIR 1974). En el texto se hace un llamado al sacrificio partidario y a abandonar el individualismo, defecto asociado a la sociedad burguesa y que debía ser combatido como una suerte de "enemigo interior", llevando la lucha política al ámbito de la subjetividad de los militantes.

Así, era preciso abandonar los proyectos personales e individuales en favor de la revolución, proyecto colectivo que acontecía, evidentemente, en el terreno de lo público.

Asimismo, este texto sostenía que la transformación de la militancia debía ser integral, involucrando tanto su vida pública como privada, promoviéndose una suerte de colonización de lo privado y personal por parte de lo público. Así podemos leer:

\footnotetext{
No es una parte -la parte pública- del militante la que está dentro del Partido mientras que otra -la parte privadaqueda fuera y sometida a otras leyes, normas y valores morales; el militante revolucionario debe ser tal, tanto en su actividad política como en su actividad privada y en ambas debe constituirse en ejemplo de una nueva moral y del inicio del proceso de constitución del futuro hombre total del socialismo (MIR 1974)
}

Podemos observar que el proyecto revolucionario no consideraba una revalorización de las relaciones personales sino que más bien, establecía que la esfera de lo íntimo debía subordinarse a las exigencias de la gran política. Por lo mismo, la dinámica de los vínculos afectivos primarios estaba condicionada por los ritmos de la revolución.

Esta perspectiva asumió que las transformaciones sociales y políticas ocurrían, necesariamente, en el ámbito de lo público. En este punto, vale la pena detenerse en la crítica 
que algunas teóricas feministas han realizado a este enfoque que distingue lo privado de lo público como dos esferas autónomas y excluyentes.

Desde el campo de la teoría política Carol Pateman ha señalado que el liberalismo comprende que las desigualdades e injusticias presentes en el ámbito privado son irrelevantes para las cuestiones asociadas a la esfera pública, de modo que esa perspectiva liberal opera invisibilizando la subordinación de las mujeres en un orden considerado como universal, igualitario e individualista. La idea de "separados pero iguales" que reconoce que ambas esferas son independientes pero igualmente valiosas y necesarias, esconde una estructura social desigual y el carácter patriarcal del liberalismo. A la teoría Lockeana que establece que mientras la familia se sostiene en vínculos naturales de consanguineidad y sentimientos, la esfera pública se rige por criterios de éxito, derechos universales y propiedad, Pateman reclama la estrecha e íntima relación entre la vida doméstica y la esfera pública (Pateman 1996).

Por su parte, la teórica feminista Linda Nicholson critica al pensamiento marxista por excluir de su teoría de la historia a las actividades reproductivas

¿Por qué tendríamos que eliminar los cambios en la reproducción o en las prácticas de la crianza de los hijos de nuestra teoría de la historia o tenerlos como temas menos importantes que los cambios que implican las actividades de producción de alimentos y objetos? (Nicholson 1990: 40).

De acuerdo a esta autora, Marx, al desconocer la historicidad de las actividades reproductivas $y$ de quienes las ejercen, las acepta como inscritas en el orden de lo "natural" o como subproductos de los cambios en la economía.
Y asimismo, al atribuirle autonomía a lo económico, desconoce la influencia de factores como la cultura, el género, la religión y la política en los juegos del mercado. Nicholson establece además que las relaciones de género operan como un elemento constitutivo de las relaciones de clase, ya que inciden en el acceso diferenciado de hombres y mujeres al control de las "actividades productivas".

De este modo, así como el liberalismo ha establecido una línea divisoria entre la familia y el Estado, el pensamiento marxista ha diferenciado lo productivo de lo reproductivo, universalizando aspectos de la sociedad capitalista -la autonomía del mercado- a sociedades precapitalistas, en las que las cuestiones de género y de clase estaban profundamente imbrincadas. Esa supuesta autonomía de lo económico respecto a otros agentes sociales se puede cuestionar incluso en las sociedades capitalistas.

Señaladas estas perspectivas críticas, podemos constatar que en el marco de la cultura política revolucionaria del MIR, la vida privada era relevante en la medida que debía supeditarse a las exigencias de la vida política que la militancia había elegido. El proyecto revolucionario se proponía la transformación radical de la sociedad desde una perspectiva universalista y masculina, centrada en la figura del "cuadro político".

Como señala Patricia Zalaquett, los militantes ejemplares eran aquellos "dispuestos a desprenderse de sus propias necesidades en pos de las necesidades de otros" (Entrevista 2014). Ocurría entonces, lo que la socióloga argentina Alejandra Oberti ha descrito como el "borramiento de sí mismo" en el colectivo (2014) 
operación que funcionó en base a dos premisas: primero, que la vida propia era menos importante que la vida de otros -el pueblo, los oprimidos, los pobres del campo y la ciudad-, categorías tan abstractas como universales frente a la particularidad del yo; $y$, segundo, que el yo debía diluirse en el colectivo, en la organización, en el Partido, lo que se manifestaba en el mandato a renunciar a todo aquello que expresara esa individualidad (Vidaurrázaga 2012).

Los sacrificios realizados por los dirigentes de la organización desde los inicios de la vida militante debían ser emulados por quienes pretendieron seguir los pasos de los líderes, cuestión que se realizaba por convicción y decisión personal y libre, y a la vez era demandado por la organización.

En este marco, priorizar lo personal era expresión de una falta de compromiso con la causa política, egoísmo individualista que no tenía lugar entre quienes integraban la vanguardia revolucionaria. Aquellos que expresaron temores, dudas o plantearon alternativas alejadas de la norma, fueron considerados quebrados o traidores por sus propios pares. Así lo recuerda Gladys Díaz, una de las pocas mujeres que integró el Comité Central del MIR, señalando:

...uno o dos días después que se levantó el toque de queda del Golpe, a mí me llega la información de que una compañera nuestra, periodista, quiere hablar urgente conmigo (...) y ella me dice, 'Gladys, por el tremendo respeto que te tengo, me dice, yo quiero hablar contigo para contarte que me voy (...) no quiero que mi guagua se desarrolle dentro de mi guata con este nivel de tensión, de angustia, y entre tiros para allá... así que yo me voy' (...) Yo le traté de convencer de que se quedara ¿no?, y el planteamiento de ella, era un planteamiento absolutamente lógico (...) no quiero estar a salto y mata, digamos, arrancando por arriba de los tejados, ni nada de eso', y ella me dijo 'Tu deberías irte, porque tienes un hijo y qué sé yo'. Para mí se había quebrado la compañera (Entrevista 2014).
La noción de "quiebre", usada habitualmente para referirse a aquellas personas a quienes, en el marco de la tortura, se les arrancó información -los "quebrados"-, es utilizada en este testimonio para señalar una conducta que se alejaba del ideal militante, ampliando sus sentidos y asociando el fantasma de la traición a una diversidad de conductas posibles (Ruiz, 2013). La misma idea está presente en el documento partidario Notas para la formación de los cuadros, que indica:

\footnotetext{
El Partido Revolucionario debe transformar a sus militantes, convertirlos en acero bien templado, sensible y flexible, pero no quebradizo, capaz de hacer frente tanto a las incitaciones de la sociedad burguesa a una vida cómoda, al individualismo, al provecho personal, como de hacer frente a la represión, a la persecución, a la tortura, capaz de continuar la lucha con más fe en el triunfo del proletariado que nunca... (MIR 1974).
}

De acuerdo al texto, un buen militante debía ser como el acero bien templado, flexible pero no quebradizo; poniendo en valor conductas asociadas al coraje, la decisión, la renuncia y la fortaleza, y rechazando a su vez aquellos gestos que revelaran fragilidad, dudas, temores o preocupación por la propia integridad. Quiebres de cuerpos militantes que para ser íntegros y completos debían obedecer las instrucciones partidarias, sin importar los costos, daños y dolores personales que ello supusiera. Como ya señalamos, el sacrificio fue a la vez una suerte de ofrenda que los militantes realizaron voluntariamente a la revolución, y una exigencia del Partido, requerimiento que a momentos adquirió un innegable tono imperativo. Un documento que expresa cabalmente lo señalado se titula, de modo elocuente, Compromiso (Sandoval 2015), texto de fecha imprecisa que circuló entre los militantes que deseaban regresar al país en forma clandestina en el marco de la Operación 
Retorno, y que expresa la preocupación de la Dirección partidaria respecto a los problemas de seguridad que golpeaban a la organización, señalando de modo claro, preciso y detallado los compromisos que debía asumir la militancia que deseaba sumarse a ese plan.

En primer lugar, llama la atención el alto grado de formalidad exhibido por el texto, imitando un lenguaje de tipo legal para señalar obligaciones y deberes y, junto con ello, anunciando -de un modo menos preciso- la existencia de sanciones para las faltas y posibles incumplimientos de los mismos. Redactado en primera persona, tal como una declaración notarial, el documento señala: "Por medio del presente compromiso revolucionario, hago constar la firme decisión de asumir los siguientes deberes", enumerándose a continuación una a una las tareas, compromisos y obligaciones entre los que destacan:

\begin{abstract}
respetar escrupulosa y conscientemente las normas de seguridad (...); trasladarme a Chile u otro país que se me indique en el momento que el Partido lo determine; luchar tenaz e incansablemente a costa de mi vida si fuese necesario para cumplir la línea política del Partido... (Sandoval 2015:271).
\end{abstract}

De esta manera, aquellos mandatos que surgieron como conceptos articuladores de la identidad mirista en los primeros años de vida de la organización, una década más tarde se articulaban en un texto claramente normativo, que incluía deberes y sanciones, y en el que la autoridad máxima, encargada de velar por el cumplimiento del compromiso y de castigar las eventuales faltas o transgresiones, estaba encarnada por el Comité Central del Partido, señalándose en las últimas líneas del documento:

Declaro finalmente que estoy dispuesto a aceptar las sanciones que el Comité Central del Partido, depositario de este documento, acuerde ante cualquier violación de mi parte del presente compromiso (Sandoval 2015:271).
El texto expresa la preocupación de los dirigentes respecto de la vida personal y familiar de sus militantes y cómo esta vida podía poner en peligro el proyecto del MIR, indicando:

Deberé subordinar mis relaciones afectivas $y / 0$ familiares al cumplimiento cabal de todas las tareas y responsabilidades que se me asignen, llegando si es preciso a separarme de esas personas por planes indeterminados (Sandoval 2015:271).

Esta separación fue un hecho para la gran mayoría de quienes volvieron a la lucha clandestina durante la Operación Retorno y dejaron a sus hijos al cuidado de otras personas. En algunos casos en manos de familiares (en Chile u otros países) y en otros, a cargo del llamado "Proyecto Hogares", solución dada por el MIR para que pudieran retornar a Chile ambos padres militantes, y que consistió en dejar a los niños en Cuba en "familias sociales" con un adulto -otro militante- a cargo de su cuidado.

El deseo de mejorar la vida de todos los niños y niñas chilenos fue la razón esgrimida para dejar a los hijos propios en manos de otros adultos, de modo que la separación y el abandono se hizo en nombre de una abstracción ("los niños de Chile y el mundo"). Así se observa en la carta de una de las madres que participó de la "Operación Retorno", Cristina Chacaltana, donde le señala a su hijo pequeño lo siguiente:

\begin{abstract}
Nosotros queremos que todos los niños tengan un techo para vivir, que tengan para comer, que tengan donde estudiar, que tengan las calles libres, donde jugar, donde no haya ningún impedimento para hacerlo. Sabemos que esto es un sacrificio enorme, porque hoy nos significa el dejarte, y el cariño que tenemos por ti, es inmenso; eso Germancito, no lo dudes jamás. Es muy doloroso, pero queremos que el día de mañana, los niños que viven en Chile, vivan junto a sus padres (Carta 1980).
\end{abstract}

La militancia que dejó a sus hijos en Cuba, cumplía con tres aspectos señalados en los 
mandatos partidarios: postergar la familia en favor del proyecto partidario; asignar prioridad a las necesidades colectivas y públicas antes que a las individuales y privadas; y promover la formación de futuros revolucionarios. Los niños del Proyecto Hogares quedaron al cuidado y formación de otros militantes -y no de un familiar que podía no compartir los ideales partidarios- y en Cuba, la patria de la revolución socialista. Como le señala la militante recién citada a su hijo: "(en Cuba) tendrás todo lo que un niño debe tener, amor, educación, trabajo, solidaridad, aquí tendrás asegurada tu vida" (Carta 1980).

En esta carta se instruye amorosamente al hijo en el ideario revolucionario, indicándole cómo debía comportarse en su ausencia:

tú tienes que poner mucho de tu parte para que el día de mañana, seas un gran revolucionario, como lo han sido los cubanos siempre; para que el día de mañana, estemos orgullosos de ti (Carta de Cristina 1980).

Cuba no solo era un espacio protector y protegido, puesto que los infantes estaban fuera del alcance de las fuerzas represivas chilenas, sino también, la encarnación del sueño socialista latinoamericano y por ende, el mejor lugar para que esos niños y niñas crecieran como verdaderos y auténticos revolucionarios (Vidaurrázaga 2018).

Ahora bien, más allá de la regla, el compromiso firmado y la orden partidaria, hubo hombres y mujeres que en no pocas ocasiones desatendieron esas normas para ver a sus hijos e hijas, visitar a las parejas o a sus padres, gestos que, desde la disciplina partidaria de una organización que estaba clandestina enfrentando una durísima represión, fueron leídos como errores graves que ponían en riesgo al Partido. En el testimonio escrito de un ex dirigente, podemos leer el comentario enjuiciador que le hace otro militante respecto de una caída sucedida poco después del Golpe de Estado:

No podemos seguir cometiendo errores. Si Federico cayó es porque violó huevonamente las medidas de seguridad. A quién se le ocurre visitar a la mamá. Hizo lo mismo que Andrea que, por juntarse con su compañero, terminó cayendo con él (Rivas 2004:42)

Las transgresiones a esas normas de seguridad se explican por la imposibilidad de disociar los afectos privados de las demandas que exigía en ese momento el proyecto político, leyéndose como debilidades de quienes no pudieron sostener esa disociación, aun conscientes de los riesgos asociados a la vulneración de esa norma. Por otro lado, hay que considerar que muchos de ellos se enfrentaron a situaciones límite asociadas a la falta de recursos, puesto que la organización no siempre logró resolver la mantención de quienes se encontraban clandestinos, precariedad los obligó a buscar apoyo en sus redes más básicas -la familia y amigos- con los riesgos que ello supuso.

Esa disociación fue imposible de sostener para muchos militantes, que se sintieron obligados a elegir entre opciones que aparecieron como excluyentes. Así lo recuerda Alfonso, quien fue convocado a participar en la ya mencionada Operación Retorno y que se negó a separarse de su hija:

\footnotetext{
Recuerdo que yo le planteé al dirigente que me entrevistaba (...) que tengo mi hija chica...tendríamos que separarnos. Y (...) nos habló de que había lugares en Cuba donde iban a quedar los niños con familias cercanas al MIR en Europa, en fin. Y eso me dolía mucho a mí. Yo quería mucho a mi hija... no podía asumir eso de tener que separarme de ella, es decir, no... no me daba la fuerza o el cuero como quieras llamarle. Le pregunto yo a él entonces qué pasa con los compañeros que están
} 
volviendo, porque esta Operación ya había empezado un año y medio antes. Me dice: bueno la gente que está volviendo nosotros pensamos que el tiempo de sobrevida es de seis meses. Entonces yo me cagué todo por supuesto. ¿Me entiende? Le planteé al final de que por qué no nos enviaba a algún país cercano primero para ir nuevamente entrando en contacto con la lucha concreta y la respuesta que recibí fue que si no estaba en condiciones de asumir el compromiso de volver, el Partido no podía gastar tiempo ni recursos en alguien que simplemente se iba a quebrar si lo mandaban a Argentina, Perú o cualquier otro lado.

(Entrevista 2017).

En el escenario descrito por Alfonso, la vida afectiva- familiar aparecía como un obstáculo respecto del cumplimiento de las obligaciones partidarias. Aunque los militantes buscasen alternativas intermedias, hubo momentos en que no fue posible articular lo militante con lo afectivo. Lo primero exigía renunciar a lo segundo y la organización no disponía ni del "tiempo ni de los recursos" para sostener a militantes que expresaban dudas o temores, es decir, potenciales "quebrados". En este caso, el militante estaba de acuerdo políticamente con la decisión partidaria del retorno, sin embargo, se sintió incapaz de cumplir esa exigencia, incapacidad que él mismo asocia a un problema subjetivo (no de divergencia ideológica) asoció a un rasgo o conducta "pequeño burguesa".

La vida de quienes ingresaron clandestinamente al país también estuvo cruzada por estas tensiones. Las exigencias de la clandestinidad en el marco de la represión dictatorial supusieron la necesidad de mantener las emociones bajo control, impidiendo que cualquier "desborde" llevase a los militantes a realizar acciones o gestos fuera de lo estrictamente permitido. El mandato de no acercarse a los seres queridos exigió altos niveles de autocontrol y es recordado por mucho de los militantes como uno de los aspectos más difíciles de sobrellevar.
Más allá de estos criterios operativos, en que la escisión y tensión entre la vida afectiva-familiar y la militancia se resolvió a favor de la segunda, en la cultura partidaria se desplegaron códigos, formas, modos de ser y actuar que pusieron en valor rasgos y conductas asociadas a la masculinidad. La exaltación de valores como el arrojo, la fuerza y la valentía (en oposición a la manifestación de las emociones, temores y dudas, todas ellas expresiones de fragilidad mandatada a la feminidad expresaron el despliegue de una masculinidad revolucionaria siempre heterosexual. Tal como recuerda Carlos Sandoval respecto de su participación en los ochenta:

\footnotetext{
me acuerdo que no pude llorar 'porque los hombres no lloran', menos lo podía hacer un revolucionario; para nosotros estaba reservado solo 'tomar la bandera del compañero caído y seguir la marcha (2015:97).
}

Esta exigencia se exacerbó en la clandestinidad, cuando quienes militaron asumieron un personaje, y debían evitar -en teoría- conocer cualquier aspecto de la vida privada de los otros militantes, ylas emociones debieron dar lugar a una frialdad que permitiera estar alerta y responder rápido ante el peligro como posibilidad constante.

Cecilia Radrigán recuerda el momento en que su pareja murió en un enfrentamiento del que ella logró huir. Para romper el cerco, se desplazó sin evidenciar emoción, controlando el dolor y la angustia, con el fin de sobrevivir. Sin embargo, cuando ya se encontraba fuera del alcance de los servicios represivos, la manifestación de sus emociones provocó en sus compañeros sospecha y preocupación. Más aún, sus superiores la calificaron como "quebrada", poniendo en duda sus competencias revolucionarias. Ella lo recuerda en los siguientes términos: 
...me voy a la casa de seguridad que teníamos en conjunto, donde vivían dos amigos que eran ayudistas y que después fueron miristas. Ellos ven mi cara y yo hasta ese momento impávida con la cara así, sin una lágrima ni nada, cara de palo, porque sentía que toda la gente me miraba. Llego a la casa, agarro al chico, 'Mataron al Negro pero sale por otro nombre, en un enfrentamiento', 'no' me dice, 'sí' le digo, y llama al otro compadre. Él se estaba bañando y sale en pelotas, y ponen las noticias y ponen justo un flash y había llegado la televisión y lo muestran y todo eso y ahí yo me pongo a llorar, ahí yo me acuerdo que estaba, buuu, me derrumbé, me senté en el suelo, lloraba, lloraba y maldije a todo el mundo, que creo que es una de las cosas buenas que hice, aunque después pensaban que yo me había quebrado, que me querían mandar para afuera y todo eso, esa guevá también es típica del machismo, que no hay que tener sentimientos (Entrevista 2013)

El dolor debía ocultarse tanto hacia "afuera", es decir, aquellas personas que no sabían que convivían e interactuaban con un integrante de la resistencia clandestina, como hacia "adentro", puesto que entre los propios compañeros se debía ocultar las emociones cuya expresión podía ser entendida como debilidad.

La tensión entre lo privado y lo público como un aspecto central de la crisis que enfrentó la organización a fines de los setenta fue abordada tempranamente por el historiador y ex militante Gabriel Salazar. En un documento elaborado en el exilio en Inglaterra en 1980 y en el marco de su negativa -junto a otros militantes respecto de sumarse a la Operación Retorno-, señaló que era preciso redefinir el concepto de "cuadro político profesional", puesto que esa noción de la militancia tenía como modelo a la "efigie de Guevara" y no respondía a la realidad histórica del proletariado chileno, formado por sujetos de carne y hueso que tenían familia, trabajo, vecinos, es decir, una vida social que no debía ser anulada por el Partido. Más bien, señaló Salazar, el trabajo político debía nacer desde esa vida social, a partir de, y no a costa de ella.

\begin{abstract}
Es absurdo sancionar como práctica "pequeño burguesa" el hecho de tener familia, amigos, identidad social concreta, es decir, realidad social y proletaria. No es posible recortar del sujeto social revolucionario todo lo que lo hace, precisamente social. No es posible amputarle su trabajo, su barrio, su familia para crear un "samurái político". (...) Es demencial por tanto expulsar militantes -o amenazar con hacerlo- porque no renuncian a su familia, a su lazo social, a su identidad concreta y porque no aceptan el "plan de retorno" individual (antisocial) que el partido les exige. Ese plan constituye una política irreal, antiproletaria y machista" (2015: 117).
\end{abstract}

\section{A modo de conclusión: Enteros, quebrados y traidores.}

El análisis de las experiencias militantes del Movimiento de Izquierda Revolucionaria hace posible identificar el modo en que, tempranamente, se fue configurando una moral partidaria con rasgos claramente definidos. La articulación entre pensamiento leninista -la noción de partido de cuadros y de vanguardia revolucionaria- y guevarismo - la propuesta de "Hombre Nuevo" y la dimensión moral de la militancia- dieron origen a un universo de representaciones con imágenes, símbolos, valores y mandatos que modelaron la experiencia de los y las miristas.

Es así como, en los documentos fundacionales de la naciente organización, ella se define a sí misma como representante de valores asociados a la pureza, la consecuencia, la lealtad y el coraje revolucionario. Se intentó así, establecer un sello diferenciador respecto de los partidos de izquierda que le eran contemporáneos a quienes acusó de ser reformistas y revisionistas. Como señala el historiador Marcelo Casals, para el MIR "(el PS y el PC) habrían traicionado los intereses del proletariado con sus inadecuadas conductas sistémicas" (2010: 146). De este modo, se construyó un discurso articulado en 
base a binarismos básicos pero efectivos, a saber: leales, puros, valientes, consecuentes versus traidores, reformistas, colaboracionistas, cobardes. Para dar sustento a ese enfoque, el MIR reivindicó para sí la condición de real "heredero" del legado de Luis Emilio Recabarren -figura fundacional del movimiento obrero en Chile- buscando en los orígenes de la izquierda política organizada una prueba de autenticidad revolucionaria.

Este doble movimiento -distanciamiento de los partidos históricos de izquierda contemporáneos y la definición de su identidad en una figura temporalmente remota- logró articular una identidad fuerte en el sentido de que consiguió -y con éxito- ser reconocida por las otras organizaciones políticas de la época como una propuesta diferente y con rasgos propios. Esta mirada hacia el pasado y la reivindicación de ese pasado para sí, no puede no ser considerado como un gesto audaz, más aún si consideramos que Recabarren fue el fundador del PC -cuya primera denominación fue Partido Obrero Socialista-, organización que fue una de las principales adversarias del MIR en el campo de la izquierda chilena.

La lectura de documentos partidarios y el análisis de los testimonios permiten observar aquellos rasgos que el MIR ponía en valor y aquellos que consideraba execrables. Sus miembros debían seguir modelos, ejemplos y conductas bien definidas, de modo que la militancia no consistía en la mera adhesión a una ideología o programa político, sino que exigía -a veces de un modo bastante categórico- adoptar un estilo de vida que suponía entregar el cuerpo y el alma a la causa revolucionaria. Un aspecto central de este "modo de ser revolucionario" tenía relación con la exigencia de subordinar la vida privada e íntima a las decisiones de la organización (figura que aparecía mimetizada con la noción de revolución y de pueblo). La intervención partidaria de la vida privada de los militantes no implicó en ningún caso una valoración de ésta última. Lejos de la consigna acuñada por el feminismo "lo privado es político" que suponía una valoración de la esfera íntima y privada de las personas, la razón revolucionaria entendía que se trataba de asuntos que debieron postergarse $o$ anularse en función de las urgencias políticas.

Esos marcos valóricos y el universo de representaciones de la organización tenía una marca de género que difícilmente puede ser ignorada. La asociación de la debilidad, la cobardía y la traición con lo femenino puede ser observado en la "Declaración de principios del MIR" y en otros documentos partidarios. Asimismo, la hombría, "tener huevos", eran rasgos y características asociadas al modelo de buen revolucionario, figura siempre masculina que destacaba por su audacia, disciplina, fortaleza, valentía y valor a toda prueba.

Por último, nos interesa destacar la idea de que el ethos mirista, con todas sus figuras, símbolos, ejemplos y valores, fue elaborado en los primeros años de vida de la organización, mucho antes del golpe de estado de 1973. Ciertamente, los distintos contextos históricos agudizaron algunos de sus rasgos y debilitaron otros, pero la idea del sacrificio, la entrega total, el "borramiento de sí en el colectivo" estuvieron presentes desde los orígenes del MIR y no logran explicarse solo como respuesta o reacción a la represión dictatorial, a la luz de testimonios de quienes pasaron por periodos tan diversos como la Unidad Popular, el exilio o el retorno clandestino, manteniéndose estas 
lógicas de entrega total al proyecto, que fueron a la vez voluntarias y exigidas por el partido.

Finalmente, a lo largo de este trabajo hemos intentado realizar un análisis histórico que ponga atención a la dimensión cultural de la política, permitiendo observar no sólo las acciones realizadas por los sujetos-en este caso los militantes del MIR- sino también las orientaciones que las guiaron, los marcos valóricos y emocionales que los movilizaron y - tal vez lo más relevante desde nuestra perspectiva- el modo en que esos valores y esas ideas fueron vividas y sentidas por las personas (Williams 2009).

\section{Bibliografía}

Carnovale. V. 2011. Los combatientes. Buenos Aires: Siglo XX.

Casals, M. 2010. El alba de una revolución. La izquierda y el proceso de construcción estratégica de la "vía chilena al socialismo" 1956-1970. Santiago: LOM.

Casullo, N. 2007. Las Cuestiones. Buenos Aires: Fondo de Cultura Económica.

Fernández, F. 1999. Escritos Revolucionarios. Madrid: Catarata.

Gaudichaud, F. 2004. Poder popular y los cordones indutriales. Testimonios sobre el movimiento popular urbano chileno. 19701973". Santiago: Lom.

Goicovic, I. .2016. Trabajadores al poder. El MIR y el proyecto revolucionario en Chile. 1965-1994. Santiago: Escaparate.

Lechner, N. 1986. La Conflictiva y nunca acabada construcción del orden deseado. Madrid: Siglo XXI.

Lechner.1988. Los Patios interiores de la Democracia: Subjetividad y Política. Santiago: FLACSO.

Leiva, S. 2010. Revolución Socialista y Poder Popular. Los casos del MIR y el PRT - ERP 1970- 1976. Santiago: Escaparate

Movimiento de Izquierda Revolucionaria (MIR). 1974. "Notas sobre la formación de los cuadros". Disponible en Centro de Documentación de Los Movimientos Armado (CEDEMA): http://www.cedema.org/uploads/NOTAS20SOBRE\%20 LA20FORMACION20DE20LOS20CUADROS.pdf (consultado en marzo 2017)

Naranjo, P., Ahumada, M., Garcés M. y Pinto J. 2004. Miguel Enríquez y el proyecto revolucionario en Chile. Discursos y documentos del Movimiento de Izquierda Revolucionaria MIR. Santiago: LOM.

Nicholson, L. 1990. "Feminismo y Marx: Integración de parentesco y economía". Teoría feminista y teoría crítica. Ensayos sobre la política de género en las sociedades de capitalismo tardío". Benhabid, S.y Cornella, P. Valencia: Editorial Alfons el Magnanim. P.40.

Oberti, A. 2014. Las revolucionarias. Militancia, vida cotidiana $y$ afectividad en los setenta. Buenos Aires: Edhasa.

Ortega, M. y Radrigán, C. 1998. Con vista a la esperanza. Santiago: Escaparate

Ortiz M. 2013. "La violencia en la construcción identitaria mirista, una perspectiva generacional (1965-1969)". Izquierdas 15: 125-140.

Palieraki, E. 2014. ¡La revolución ya viene! El Mir chileno en los años sesenta. Santiago: Lom.

Palma, J. 2012. El MIR y su opción por la guerra popular. Estrategia político-militar y experiencia militante 1982-1990. Concepción: Escaparate.

Pateman, C. 1996. "Críticas feministas a la dicotomía público/ privado". Perspectivas feministas en teoría política. Castells, C. (comp.). Barcelona: Paidos.

Pérez, C. 2003. "Historia del MIR. 'Si quieren guerra, guerra tendrán". Estudios Públicos 91.

Pinto, J. 2006. "¿Y la historia les dio la razon’? El MIR en dictadura 1973-1981". Su revolución contra nuestra revolución. Izquierdas y derechas en el chile de Pinochet. Vol I. Valdivia, et al. Santiago: LOM.

Rivas, P. 2004. Territorios fragmentados. Santiago: CEMEArchivo Chile.

Ruiz, O. 2013. "Mandatos militantes y quiebres en el Movimiento de Izquierda Revolucionaria (MIR) en Chile". Revista Nuevo Mundo Nuevos Mundos (Nouveau Monde Mondes Nouveaux, Francia.

Ruiz, O. 2014. "Historias y memorias de traición. Subjetividad revolucionaria, mandatos militantes y traición en el Partido Revolucionario de los Trabajadores-Ejército Revolucionario del Pueblo (PRT-ERP), Montoneros y el Movimiento de Izquierda Revolucionaria (MIR) en las décadas del sesenta y setenta". Tesis para optar al grado de Doctora en Estudios Latinoamericanos, Universidad de Chile, Santiago.

Ruíz, O. 2018. "Muertes luminosas, vidas en la oscuridad. Heroísmo y traición en la militancia revolucionaria de los setenta en la Argentina y Chile, Izquierdas, 40, junio 2018:202-230

Salazar, G. 2015. El tranco del pueblo. Alternativas políticas de la izquierda revolucionaria. Santiago: Proyección.

Salinas, S. 2013. El Tres letras. Santiago: Ril editores.

Sandoval, C. 2014. Movimiento de Izquierda Revolucionario 1965-1970. Coyunturas, documentos y vivencias. Tomo I. Santiago: Quimantú.

Sandoval, C. 2015. "Compromiso". Historia del MIR, Tomo 4, 
1980-1986. Santiago: Quimantú.

Silva, R. 2011. Resistentes y clandestinos. La violencia politica DEL mir EN LA DICTADURA PROFUNDA, 1978-1982. Concepción: Escaparate.

Subercaseaux, B. 2004. Historia de las ideas y de la cultura en Chile. Volúmen III. Santiago: Editorial Universitaria.

Vera, A. 2011 Tortura, clandestinidad y dictadura. Una mirada desde la militancia mirista 1982-1984. Concepción: Escaparate. Verdery, K. 1999. The Political Lives of Dead Bodies. Reburial and Postsocialist Change. New York: Columbia University Press.

Vidaurrázaga, T. 2006. Mujeres en rojo y negro. Reconstrucción de la memoria de tres mujeres miristas 1971-1990. Santiago: Editorial Escaparate.

Vidaurrázaga. 2012. "La escisión entre lo individual y colectivo en la moral militante de la Nueva Izquierda". Revista Sujeto, Subjetividad y Cultura 4: 37-45

Vidaurrázaga, 2018. "Pequeños compañeritos. Los hijos del MIR y Montoneros en los hogares colectivos de Cuba". En: Alonso J., Horwitz E. y Peñaloza C. Exilios del sur: género, generación y clase (título provisorio). Santiago: Editorial Cuarto Propio. En Prensa.

Vitale, L. 1999. Contribución a la historia del Mir. Santiago: Ediciones Instituto de Investigación de Movimientos Sociales "Pedro Vuskovic".

Williams, R. 2009. Marxismo y literatura. Buenos Aires: Editorial Las Cuarenta.

Tarcus, H. 1998. "La secta política. Ensayo acerca de la pervivencia de lo sagrado en la modernidad". El Rodaballo 9: 54. 